\title{
Determinación de la rentabilidad privada de la gestión de residuos sólidos urbanos del municipio de Corrientes, provincia de Corrientes. Período 2010- 2020
}

Lic. Viviana Bercheñi; Lic. María José González Gervasoni. (*)

1. Resumen del Proyecto:

El problema de los residuos sólidos ha ido cobrando importancia en las ciudades modernas. El avance de la urbanización, vino acompañado de mayor producción de residuos, y con ello la aparición de cada vez más basurales clandestinos (terrenos baldíos, cauces de ríos o arroyos, espacios públicos, etc.); incluso el sitio de disposición final no siempre cuenta con los controles de saneamiento requeridos, o está acorde a las necesidades de la población.

Existe en ciudades modernas, una forma alternativa de producir que se realiza mediante la utilización de nuevas técnicas de gestión de residuos, como por ejemplo la minimización, para lo cual es necesaria la adopción de medidas organizativas y operativas que permitan disminuir, hasta niveles económica y técnicamente factibles los residuos desechados. (Cardona Gallo M; 2006)

La ciudad de Corrientes no escapa a esta problemática mundial. Estudios realizados en la región, ponen de manifiesto que entre los mayores problemas ambientales que presentan las ciudades intermedias de las provincias del Nordeste Argentino (NEA), se encuentra la incorrecta gestión de residuos sólidos urbanos (Berent, Mario R. - Vedoya, Daniel E., 2004).

Este diagnóstico y el gran desafío que representa la gestión integral de residuos sólidos para nuestra ciudad, fueron disparadores de esta investigación; que pretende generar y evaluar un modelo aplicable a la ciudad de Corrientes, acorde al crecimiento demográfico previsto para la década 2010 2020, y orientado hacia la recuperación de material susceptible de ser comercializado.

Así, mediante el análisis desagregado de los residuos sólidos urbanos generados por los habitantes de la Ciudad de Corrientes, y las proyecciones realizadas para el período 2010-2020, se determinó la inversión inicial 
requerida y los costos de implementación de un sistema GIRSU (Gestión Integral de Residuos Sólidos Urbanos) por parte de la Municipalidad. Asimismo, se evaluó el impacto monetario de los componentes susceptibles de ser recuperados y comercializados para su posterior incorporación a cadenas productivas; tratando de constatar el grado de influencia en los recursos municipales, de los ingresos adicionales generados por estas actividades de recupero.

Palabras clave: Gestión integral; residuos sólidos urbanos; recupero; comercialización; sustentabilidad.

\section{Introducción:}

En la Ciudad de Corrientes, la gestión integral de residuos sólidos urbanos la realiza la empresa Logística Urbana S.A. que, para la disposición final de los mismos, utiliza un método denominado relleno sanitario que consiste en depositar en el suelo los desechos sólidos, los cuales sin tratamiento previo se esparcen y compactan tratando de reducir de este modo su volumen para ocupar el menor espacio posible.

La firma Lusa S.A. inició sus actividades de recolección de Residuos Sólidos y limpieza en la Ciudad de Corrientes en el año 2011; siendo su principal innovación tecnológica en la prestación del servicio, el seguimiento de las unidades por control satelital mediante sistema GPS. Esta innovación, les permite conocer en tiempo real la ubicación de cada vehículo de la flota y la duración de su recorrido.

Otro de los logros en materia de inno- vación fue la instalación de una central de monitoreo, que facilita la preparación de reportes e informes de gestión a partir de las estadísticas generadas sobre el desempeño y calidad del servicio prestado.

La aplicación de este servicio, que en el 2011 les ha permitido certificar Normas de Calidad ISO 9001-2008, otorga algunas ventajas que merecen ser resaltadas. Entre ellas:

- Reducción de tiempos ociosos de Unidades y Operarios.

- Botones anti-pánico y comunicación móvil continua.

- Control de recorridos y frecuencias.

- Mayor limpieza en menor tiempo.

E1 área de cobertura del servicio concesionado a la empresa Lusa SA, es la ciudad de Corrientes; cuya población urbana genera un total de 1.700 toneladas de residuos por semana, que deben ser recolectados en un recorrido que se extiende a 12.000 cuadras diarias.

Adicionalmente la empresa presta servicios de recolección de árboles y ramas, barrido y limpieza mecánica en las principales avenidas y paseos de la ciudad. También tiene a su cargo la gestión y erradicación de más de 80 mini basurales que se ubican en general en áreas periféricas de la Ciudad y la recolección de residuos patológicos.

Para eficientizar el proceso de recolección de residuos, la Firma ha dividido a la Ciudad en 26 zonas urbanas de intervención: 14 en turno mañana y 12 en turno noche. Simultáneamente brinda servicios de recolección de residuos especiales a grandes generadores. 
El personal afectado directamente a las tareas de recolección asciende a 260 empleados operativos del área municipal cuya retribución está constituida por la suma de Planes "Neike chamigo" (aproximadamente $\$ 4500$ ), otros planes nacionales/provinciales y un "Plus" que perciben por parte de la empresa que asciende a $\$ 4000$. E1 total promedio de retribución que perciben los empleados municipales que se encargan de la recolección de RSU asciende entonces a $\$ 12000$ aproximadamente, por jornadas de seis horas diarias (que se pueden extender a siete $\mathrm{u}$ ocho algunas veces). No existe diferencia retributiva en cuanto a los empleados que se encargan de la recolección manual de RSU y los que se encargan de manipular camiones y compactadoras. Ellos están a la espera de la firma de un contrato que los vincule directamente con la empresa LUSA, y que les dé mejores condiciones contractuales; estiman que se producirá en los próximos meses.

De la observación del desarrollo de sus tareas en áreas de recolección, se pudo comprobar que realizan su trabajo sin ropa adecuada ni elementos y herramientas que tiendan a proteger su integridad física. Recolectan bolsas de residuos domiciliarios con las manos, sin guantes, ni botas, sin barbijos ni protectores oculares, entre otros detalles. También carecen de ropa de trabajo adecuada a la temporalidad (verano e invierno). La entrevista se realizó a las 7 de la mañana con una temperatura de 4 grados centígrados y la ropa de trabajo era claramente inadecuada.

Los empleados que dependen directa- mente de la empresa Lusa S.A. ascienden a 20, cubriendo las áreas de logística, mantenimiento y administración. El servicio de recolección de residuos domiciliarios se divide en dos turnos: diurno y nocturno cuya duración es de seis horas cada uno aproximadamente.

La utilización de la flota se divide en tres turnos. El producido del barrido, erradicación de mini basurales, y servicios especiales en dos turnos: vespertino y matutino.

El pliego de condiciones particulares Anexo II-Servicio de Recolección-, en el punto $\mathrm{N}^{\circ} 4$ - Servicio de Recolección domiciliaria- aclara que "además la prestación debe contemplar una Recolección Diferenciada de Residuos Sólidos Urbanos en Origen". La empresa en la documentación presentada aclara que dicha diferenciación se basará en recolección de material húmedo y seco, distinguiendo procedimientos para ambos casos.

Servicio de recolección domiciliaria "fracción seca": la empresa se compromete a realizar una prestación convencional y consistirá en el retiro de la fracción seca de los RSU dispuesto a este fin en la vía pública, en recipientes individuales o colectivos, frente a edificios, en las entradas de vías públicas inaccesibles para camiones, o en otros lugares predeterminados. También se incluyen todos los RSU FS públicos, provenientes de cementerios, parques, escuelas, estadios, establecimientos, cuarteles, puestos policiales, etc, entre otros.

La empresa define como materiales recuperables Secos, susceptibles de comercializarse posteriormente, los siguientes: 
- Papeles y Cartones: diarios, revistas, folletos, otros impresos, cajas de cartón, envases de papel, cartón de alimentos y bebidas, envases tetrabrik, etc.

- Vidrios: botellas, frascos y envases de alimentos.

- Metales: latas de bebidas y conservas.

- Plásticos: botellas de bebidas, envases de alimentos, vajillas descartables, sillas y macetas, sachets, etc.

El Servicio de recolección domiciliaria "fracción húmeda", cuyo retiro se ajusta a normas convencionales, dispondrá para tal fin en la vía pública recipientes individuales y colectivos, frente a edificios, en las entradas de vías públicas inaccesibles para camiones, o en otros lugares predeterminados. También se incluyen todos los RSU FH públicos, provenientes de cementerios, parques, escuelas, estadios, establecimientos, cuarteles, puestos policiales, etc., entre otros.

Es importante aclarar que la recolección de RSU que efectivamente realiza la empresa en la Ciudad de Corrientes no distingue diferenciación en origen como exige la norma.

En el expediente de pre-adjudicación la empresa declara: "El Sitio que ofrece la empresa para realizar la disposición final de residuos está ubicado en el Departamento de San Cosme, de la Provincia de Corrientes, en el lugar conocido como campo "María Angélica" (ex SARPA), Municipio de Santa Ana, identificado como Lote N11 de la mensura N1023-E/78, cuya partida inmobiliaria es R20001533.
El predio está situado por Ruta Provincial $N^{\circ} 6$, al este de la Ciudad de Corrientes y a $10 \mathrm{~km}$ este noreste de la localidad de Santa Ana, entre la Ruta Nacional N'12 y la Ruta Provincial No5, distando a $30 \mathrm{~km}$ aproximadamente del centro de la Ciudad de Corrientes. El predio tiene una extensión de aproximadamente 69.5 hectáreas. Por su ubicación es óptimo para su aprovechamiento por parte de municipios situados a una distancia que haga viable el transporte basta el mismo, lo que otorgaría un uso de carácter regional".

E1 tratamiento y disposición final en el enterramiento sanitario controlado ubicado en este predio comprende los residuos sólidos urbanos, provenientes de servicios de recolección, barrido y limpieza de las calzadas de la Ciudad, y residuos sólidos urbanos de terceros, de restos de obras y demoliciones, restos verdes, residuos voluminosos, y residuos comerciales e industriales no peligrosos asimilables a los urbanos.

No incluye en sus servicios la gestión de residuos del tipo industrial líquido, semi líquido, volátil, inflamable, corrosivo, tóxico, irritante, radiactivo, explosivo, contaminante o peligroso.

E1 predio permanecerá abierto las 24 horas los 365 días del año. Las jornadas laborales se extenderán de 21 hs a 21 hs del día siguiente.

Se ejecutarán dos módulos de enterramiento sanitario controlado. E1 primero recepcionará los desechos y tendrá una vida útil de diez años. El segundo entrará en funcionamiento luego de ese plazo y por 
cinco años más que constituye el plazo de ampliación contractual estipulada.

De la entrevista realizada con personal jerárquico de la empresa, se estima que dicho predio entrará en funcionamiento a partir de enero del año 2019. Mientras esto se concrete, la empresa Venturino continúa encargándose de la disposición final utilizando el mismo método (relleno sanitario).

De la documentación analizada se desprende que la empresa Logística Urbana S.A. (LUSA) ha definido como conceptos facturables a la Municipalidad de la Ciudad de Corrientes los siguientes ítems:

- Recolección diaria, carga, transporte $y$ descarga de residuos domiciliarios nocturnos con una frecuencia de seis.

- Recolección diaria, carga, transporte y descarga de residuos domiciliarios diurnas con una frecuencia de seis.

- Recolección en días alternos, fijos. Carga, transporte y descarga de residuos domiciliarios: frecuencia (tres).

- Recolección diaria del producido del barrido, limpieza de parques y paseos, de poda y residuos voluminosos.

- Recolección diaria, carga, transporte y descarga de residuos patológicos producidos por los organismos públicos y privados de la Ciudad de Corrientes.

- Disposición final de los residuos domiciliarios, del producido del barrido de calles y avenidas, del producido de limpieza de cunetas y canales de desagües, del producido de limpieza de parques y paseos, de poda y residuos voluminosos.

Los valores acordados en el expediente del año 2016 están expresados a valores corrientes de diciembre de 2014, incluyen precios finales y por todo concepto: IVA, tasas, cargos por nacionalización, impuestos o demás cargas o gravámenes que se apliquen.

La cotización mensual que aprobó la Municipalidad asciende a $\$ 9.621 .254$

\section{Material y Métodos:}

Área de Estudio y escala de análisis:

El área de estudio fue la Ciudad Capital de la Provincia de Corrientes, con una población de 352.374 habitantes (según último Censo Poblacional del 2010), y coincidente con el área de cobertura de la concesión otorgada por la gestión municipal a la Empresa Lusa S.A.

E1 objeto de estudio: los Residuos Sólidos Urbanos producidos por sus habitantes, específicamente aquellos susceptibles de ser recuperados y comercializados, y la rentabilidad privada anual generada en el período de estudio considerado.

Instancias metodológicas y especificación de técnicas.

Para la investigación se recurrió a una metodología descriptiva. A partir del análisis tanto de fuentes secundarias que fueron recolectadas en el proceso de la investigación, como de las fuentes primarias, pudimos proponer para el municipio Capitalino, un Plan de Gestión Integral de Residuos Sólidos Urbanos, y determinar la rentabilidad privada viable a partir de la comercialización del material reciclable.

La investigación se enfocó en la generación de un modelo basado en un sistema de Gestión Integral de Residuos Sólidos Urbanos aplicable al municipio de la Ciu- 
dad de Corrientes y orientado hacia la recuperación de material susceptible de ser comercializado.

A partir de proyecciones de evolución demográfica basadas en datos y técnicas aplicadas por el Instituto Nacional de Estadística y Censos para la cuantificación de crecimientos poblacionales anuales cuyo método se denomina tasa de crecimiento poblacional promedio para períodos consecutivos (en nuestro caso 2010-2020); de la identificación de la composición de los residuos sólidos domiciliarios susceptibles de ser recuperados de la generación de residuos urbanos por $\mathrm{kg}$ /habitante /día en la provincia de Corrientes, e identificación de precios de productos recuperados y comercializados en mercados locales a valores constantes de diciembre de 2017 (según información suministrada por el Observatorio Nacional para la Gestión de Residuos Sólidos Urbanos de la Secretaría de Ambiente y Desarrollo Sustentable de la Nación); se intentó determinar un posible flujo de ingresos para la actividad de gestión de residuos sólidos urbanos bajo una órbita de explotación privada, verificando si un plan de gestión de residuos de este tipo en la Ciudad de Corrientes es económicamente rentable a través de la aplicación de instrumentos de formulación de proyectos desde una perspectiva privada.

Así, los ingresos anuales del sistema de gestión privada se obtuvieron del producto entre la cantidad de materiales recuperados por kilogramo de basura generada por habitante mes diferenciado por tipo de material (vidrio, cartón, aluminio, plásticos, hierro, etc.) multiplicado por sus respectivos precios promedios (a valores constantes diciembre 2017). Obtenidos los ingresos anuales, se realizaron proyecciones, a partir de las variaciones incrementales de la población y del volumen de basura domiciliaria.

En cuanto a los costos operativos anuales, fueron determinados a partir de los siguientes conceptos: salario promedio anual del personal afectado a la recolección, combustible, ropa y herramientas de trabajo, repuestos y mantenimiento de maquinaria afectada al sistema de gestión tradicional implementado. Todos los conceptos están expresados a valores constantes de diciembre de 2017 y fueron suministrados por profesionales técnicos de la Secretaría de Obras y Servicios Públicos de la municipalidad de la Ciudad de Corrientes.

Del cotejo de los ingresos proyectados versus los costos operativos del sistema de gestión de residuos orientado hacia el reciclaje, recupero y reutilización se determinó la rentabilidad del plan en virtud de indicadores como Valor Actual Neto (VAN), tasa interna de retorno (TIR) y relación Beneficio/Costo.

La tasa de descuento aplicable para la actualización del flujo de fondos será del $12 \%$ anual (tasa de corte usualmente utilizada para la valuación de rentabilidad de proyectos privados) y se analizaron distintas posibilidades de financiación de la inversión inicial y su impacto en el flujo de fondos proyectado.

- Fuentes primarias: observación in situ y entrevistas a funcionarios municipales, muestreo de residuos domiciliarios para el análisis de su composición. 


\section{Resultados:}

Los costos operacionales incluyen la adquisición de insumos y gastos en personal tal como se exponen en la Tabla 1. Se debe tener presente que se consideró la totalidad del personal municipal afectado a la recolección (260 trabajadores) que tienen cate- goría de Contratados en planes municipales (Neike Chamigo) cuya condición laboral es precaria. Si bien no tienen obra social, seguro de vida ni descuento jubilatorio a efectos de prever una regularización factible y fundamentada desde una perspectiva económi$\mathrm{ca}$, se incluyeron tales costos.

Tabla 1

Costos Operacionales de la gestión de RSU del Municipio de la Ciudad de Corrientes con comercialización de productos recuperables

\begin{tabular}{lcc}
\hline \multicolumn{1}{c}{ Concepto } & Valor Mensual & Total Año \\
\hline Salarios & $\$ 12.000 .00$ & $\$ 40.560 .000,00$ \\
Insumos & $\$ 5.000,00$ & $\$ 2.600 .000,00$ \\
ART & $\$ 1.500,00$ & $\$ 4.680 .000,00$ \\
Costos operacionales & & $\$ \mathbf{4 7 . 8 4 0 . 0 0 0 , 0 0}$ \\
\hline
\end{tabular}

Fuente: Cálculos propios

Los gastos operativos enunciados en la de trabajo dos entregas por año por operario. Tabla 2 incluyen gastos básicos y generales, Estos costos se estimaron a valores de mantenimiento de equipos, vehículos, segu- precios de insumos de diciembre de 2017, y ros, alquileres, entre otros conceptos. Se con- considerando un área de acción equivalente sideró para el cálculo del valor de insumos a doce mil cuadras diarias.

Tabla 2

Costos Operativos de la gestión de RSU del Municipio de la Ciudad de Corrientes con comercialización de productos recuperables.

\begin{tabular}{lcc}
\hline \multicolumn{1}{c}{ Concepto } & Valor Mensual & Total Año \\
\hline Gastos básicos & $\$ 250.000$ & $\$ 3.000 .000$ \\
Gastos Generales & $\$ 450.000$ & $\$ 5.400 .000$ \\
Mantenimiento de equipos & $\$ 115.000$ & $\$ 1.380 .000$ \\
Combustible & $\$ 194.400$ & $\$ 2.332 .800$ \\
Seguros & $\$ 1.500$ & $\$ 594.000$ \\
Alquileres (leasing) & $\$ 15.000 .000$ & $\$ 180.000 .000$ \\
Gastos Operativos & & $\$ 192.706 .800$ \\
\hline
\end{tabular}

Fuente: Cálculos propios 
Para la estimación de erogaciones en concepto de alquileres de equipos destinados a la recolección, se tomaron como valores aproximados los definidos en el presupuesto municipal del año 2017, bajo el título "Servicios no Personales" que textualmente define: "El rubro contempla el alquiler de equipos y camiones que en importante número se destinan a mantenimientos de calles, barrido y limpieza, contratación de equipos para la recolección de residuos, e incluye además créditos asignados para locaciones de obras, servicios de terceros, alquileres de inmuebles, gastos de recaudación, servicios de agua, energía eléctrica, teléfonos, correo, reparaciones, etc."

Los camiones volcadores tienen una capacidad de consumir 275 litros por tanque de combustible. El tipo de combustible se define como Euro 5. Los 33 equipos afectados a la recolección recorren 1200 kilómetros diarios. Ellos consumen de 26 a 32 litros cada cien kilómetros. A los efectos del cálculo se consideró una media de 30 litros cada cien kilómetros. Cada equipo se estima, tiene un recorrido diario de $40 \mathrm{~km}$ aproximadamente.

Dentro del concepto de mantenimiento de equipos se incluye la estimación de provisión de aceite, filtros, controles regulares, cambios de cubiertas, verificación y mantenimiento del sistema compactador, entre otros. El cambio de cubiertas se estima por camión seis cubiertas cada tres años.

Para la cuantificación de ingresos producto de la comercialización del material recuperado tal como lo expone la Tabla 3, se tomaron los precios identificados en puntos

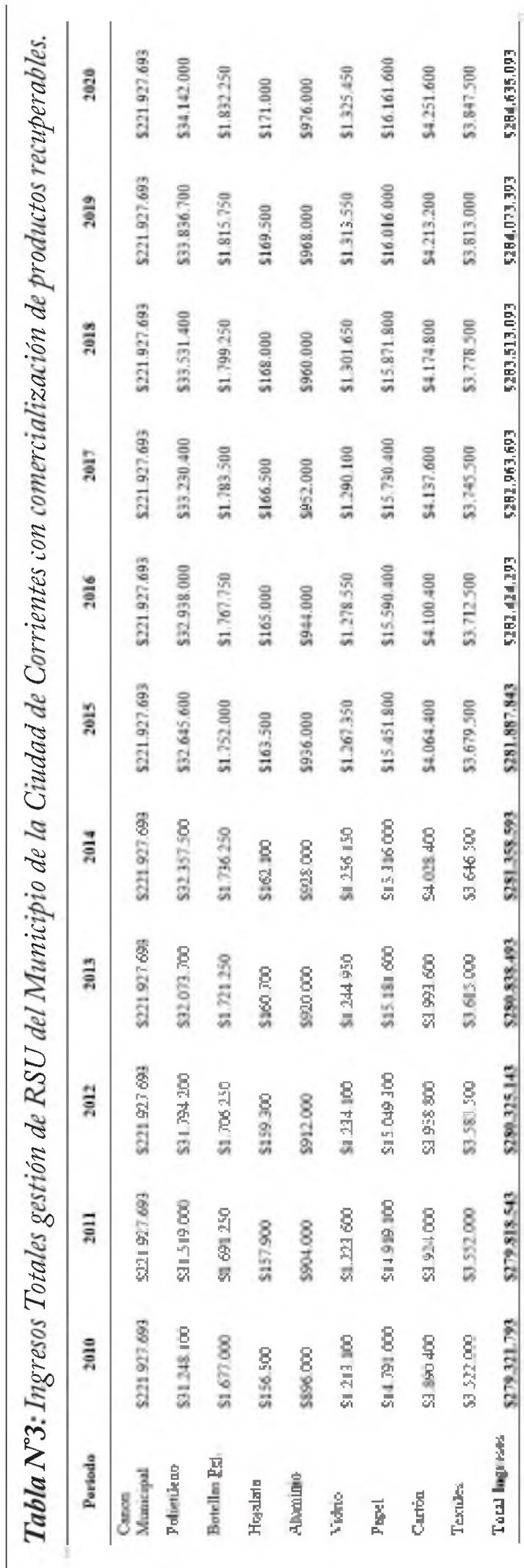


de venta nordeste para el año 2017 publicado por el Ministerio de Ambiente y Desarrollo Sustentable de la Nación. Cuando no existía un solo precio se optó por un promedio de variables posibles. Adicionalmente de consideró el canon erogado por la Municipalidad a la empresa LUSA.

La inversión inicial no implica en este caso un desembolso único en el momento cero, sino que los equipos fueron adquiridos mediante el sistema de leasing cuyo desembolso fue cuantificado dentro del concepto

\section{Tabla 4}

Cuantificación monetaria del equipo afectado a la recolección de residuos sólidos urbanos

\begin{tabular}{|c|c|c|c|}
\hline Concep1v & Unidlat & $\begin{array}{l}\text { Precin } \\
\text { Lthitnstur }\end{array}$ & Toltu] \\
\hline 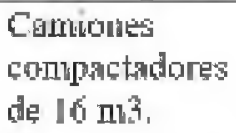 & 16 & 5400000000 & $\$ 64,00,00000$ \\
\hline $\begin{array}{l}\text { Camiones } \\
\text { yoloadors de } \\
\text { 6uts. }\end{array}$ & 9 & $\$ 3.500 .000,00$ & 531.300 .00000 \\
\hline $\begin{array}{l}\text { Camiones } \\
\text { valcadortis de } \\
15 \text { irs. }\end{array}$ & 2 & $\$ 3.500,000,00$ & 570000000000 \\
\hline $\begin{array}{l}\text { Comulous } \\
\text { wolcadores } \\
\text { equipados con } \\
\text { Grita y Balde } \\
\text { Almeja }\end{array}$ & 2 & $\$ 3.000000,00$ & S6,0NH,0HOHO \\
\hline $\begin{array}{l}\text { Barrordora } \\
\text { neculas. }\end{array}$ & I & $\$ 2.400 .000,00$ & $52.400 .000,00$ \\
\hline $\begin{array}{l}\text { Benredora } \\
\text { menanica. }\end{array}$ & 1 & $52000000_{4} 00$ & \$2,OMH, (AM, ONO \\
\hline $\begin{array}{l}\text { Furgon parr a d } \\
\text { servicia de } \\
\text { RESPA T }\end{array}$ & $t$ & $\$ 500000,00$ & Sscho, (00,00 \\
\hline $\begin{array}{l}\text { Counito } \\
\text { eléctrico gacal } \\
\text { recolecciond en } \\
\text { peatouales }\end{array}$ & 1 & $\$ 55000,00$ & $\$ 85,000,00$ \\
\hline TOTALES & & & $\$ 113,48,5,000,00$ \\
\hline
\end{tabular}

Fuente: Cálculos propios 
El cálculo del flujo financiero neto se realizó tomando como premisa los costos operativos y operacionales reales que resultan producto de un convenio entre el $\mathrm{Mu}-$ nicipio y la empresa LUSA. Se consideró el impacto (costo laboral) de la totalidad de los empleados municipales afectados a la gestión de residuos sólidos urbanos (que asciende a doscientos sesenta operarios). Se considera que la eficiencia técnica y económica tendería a reducir el número de trabajadores afectados si primaran tales criterios.

Indicadores de Rentabilidad comprobados:

VAN: \$114.930.496,55

TIR: $34 \%$

$\mathrm{RBC}=1,17$

La diferencia de ingresos provenientes de la Gestión de Residuos Sólidos Urbanos con comercialización de productos recuperables incrementaría los ingresos que se obtienen de manera tradicional aplicando el sistema actual en un 25\%. Esto redundaría en la obtención de recursos adicionales municipales que se podrían destinar a mejorar las condiciones de trabajo de los individuos afectados a esta actividad e iniciar un plan de inversiones orientadas a sistematizar y modernizar el sistema de gestión propuesto.

\section{Recomendaciones:}

Finalmente, se considera oportuno enumerar aquí algunas sugerencias:

- Control por parte del Municipio de la entrega efectiva de ropa de trabajo de la Empresa LUSA a los empleados municipales que desarrollan su actividad en la Gestión de Residuos Sólidos Urbanos de la Ciudad de Corrientes.

- Control y penalización del municipio a los vecinos que no cumplen con los horarios fijados para la recolección en los distintos barrios de la ciudad.

- Concientización a los empleados municipales sobre medidas de bioseguridad.

- Aumento de la presencia de contenedores diferenciales en lugares públicos para que el reciclaje sea factible

- Incentivación a la población de la necesidad de diferenciación de residuos en origen.

- Concientización a recolectores formales sobre las medidas de higiene pos desarrollo laboral.

- Implementación de un plan de reciclado en la ciudad orientado al fortalecimiento de recursos adicionales municipales.

- Implementación de campañas de sensibilización y educación ambiental en las escuelas.

- Implementación de mejoras en el tratamiento final de los residuos. Se recomienda abordar el análisis físico químico y bacteriológico de lixiviados eliminados por desagües improvisados del relleno sanitario operativo a cargo de la empresa Venturino S.A.

- Desarrollo de actividades de sensibilización (charlas, volantes, difusión en radio y $\mathrm{Tv}$, cartelería, etc.) a cargo del $\mathrm{mu}^{-}$ nicipio. 


\section{Bibliografía definida:}

1. Candioti E. (2002) "Administración Financiera”. Edit. Universidad Adventista del Plata. Buenos Aires.

2. Berent M. Bedoya D. (2004). "Tratamiento de Residuos Sólidos Urbanos en Ciudades Intermedias del Nea.". Ed.ITDAHu.Corrientes. Argentina.

3. Esquer Verdugo, R. (2009). "Reciclaje y Tratamiento de los Residuos Sólidos Urbanos". Santiago de Chile. Edic. UCCH.

4. Cardona Gallo, M. M. (2006). Minimización de Residuos: una política de gestión ambiental empresarial.
5. Gianneschi M (2008) "Matemática Financiera". Edic. Librería de la Paz. Corrientes, Argentina. Resistencia.

6. González, G. (2010). “Residuos Sólidos Urbanos. Argentina. Situación actual y alternativas futuras "Cámara Argentina de la Construcción. Area de Pensamiento Estratégico. Fecha de consulta 26 de junio de 2014.

7. Gutiérrez, H. (1994) "Evaluación de Proyectos ante Certidumbre ". CIADE, Universidad de Chile, Santiago de Chile.

8. Patiño J.L. (2005). "Residuos y Municipios “. Editorial Moglia Corrientes. 